\title{
A Comparison between TEFL Students with Mental Health Disorders and Normal Students in Cognitive Strategy Use in L2 writing
}

\author{
Fateme Jamshidian \\ English Department, Najafabad Branch, Islamic Azad University, Najafabad, Iran \\ f.jamshidian1@gmail.com \\ Zahra Fotovatnia \\ English Department, Najafabad Branch, Islamic Azad University, Najafabad, Iran \\ fotovatnia@yahoo.com \\ Mohammadreza Abedi \\ Associate professor, Counseling Department, University of Isfahan, Isfahan, Iran \\ dr.mr.abedi@gmail.com
}

Doi:10.5901/mjss.2014.v5n23p882

\section{Abstract}

Previous studies show that psychiatric conditions can influence educational achievements of learners. This study aims to investigate the differences between TEFL students with mental health disorders and normal students in cognitive strategy use in L2 writing. Seventy and two EFL postgraduate and under graduate students of Najafabad Branch, Islamic Azad University participated in this study. They were selected through random sampling. The materials were Quick Oxford Placement Test (QOPT), Beck Depression Inventory (BDI), Modsley Obsessive Compulsive Inventory(MOCI), writing strategy questionnaire, Semi- structured interview. Although, people with OCD and people with depression show cognitive impairment, the study indicates no difference between students with mental health disorders and normal students in cognitive strategy use. It seems that cognitive impairment in OCD and depression does not play an important role in selecting cognitive strategies in writing. Besides the findings of this study, further research is required to show the importance of psychological problems in the process of learning to language teachers in order to help learners in this respect.

Keywords: depression; L2 strategies; Obsessive Compulsive Disorder (OCD) ; mental health disorders; psychological problems; students with OCD; students with depression

\section{Introduction}

Due (2012) believed that beliefs, affective states, general factors, and previous learning experiences together with different situational factors which are considered as individual learner differences establish the learners' choice of learning strategies. Language Learning Strategies (LLS) are different activities and specific actions. Learners use them to have a clear meaning and be easy to understand their learning and to learn easier, faster, more enjoyable, more selfdirected, more effective, and more transferable to new situations (Wenden, 1987 \& OXFORD, 1990).

According to Cohen (1996), studies on LLS have viewed cognitive and meta-cognitive strategy use. These studies do not succeed in gathering, analyzing, or reporting personality-related, social, and demographic information about the subjects. Some researchers emphasized the investigation of psychological factors like personality-related, social, beliefs, attitudes, anxiety, and general personality factors such as introversion/ extroversion, reflectiveness/impulsiveness, selfconfidence, self-concept, self- creativity, and motivation (intrinsic/extrinsic) in relation to LLS. For example Cohen and Oxford ( 1992) believed that factors such as motivation, beliefs, attitudes, anxiety, learning style, world knowledge, sex, and ethnicity have received lesser emphasis. Schmeck (1988) encouraged researchers to scrutinize learning styles and learning strategies in the context of general personality factors such as introversion/extroversion, reflectiveness/ impulsiveness, field independencel dependence, self-confidence, self-concept, self-efficacy, creativity, anxiety, and intrinsic and extrinsic motivation.

Psychiatric conditions can influence educational achievements of learners and their abilities in an academic setting 
(Ghanei, Mohamadpour \& Shariatifar, 2003). Academic procrastination was related to anxiety, depression and low selfesteem (Koestern, Senecal \& Vollerand, 1995). Obsessive Compulsive Disorder (OCD) is one of the mental health disorders which is described as recurrent obsessions and compulsions that are perceived as irrational and causes significant impairment and distress (Flament \& Irak, 2009). Thoughts related to anxiety make people with OCD do obsessive actions, resulting in decreasing the severity of anxiety (Abedi , Esfahanni \& Neshatdoust, 2010). Depression is another mental health disorder in which a person has feelings of sadness, instability, loneliness, hopelessness, worthlessness, and guilt. It is a common mental disorder can cause unpleasant states of mind and can make individuals' abilities less effective to start their everyday tasks in general (Guilbert, 2007).

Based on the book Teaching Students with Mental Health Disorders (2001), students with mental health problem such as depression have difficulty concentrating and making decisions. Maintaining the attentiveness necessary for learning is difficult for them. Therefore, they have problems processing information and retrieving it. Because students with mental health problems present a challenge for teachers, this study aims to find out the differences between people with mental health disorders and normal people in cognitive strategy use in L2 writing. Finding any differences help teachers play an important role to support a student with these mental health problems. Because they see students on a daily basis, they are in a position to see and to notice warning signs of depression and OCD.

\section{Literature Review}

Broad cognitive deficit is not observed in OCD sufferers, although OCD subgroups are shown as having impairments in different areas of cognitive functioning (DeCaria, Hollander, \& Liebowitz,1989). Csigó, Demeter, Harsányi, Németh and Racsmány (2011) pointed to other researchers' findings that OCD patients have difficulties with tasks involving strategy planning, shifting of attention, inhibition of proponent responses, and self-cued memory retrieval processes. Depression comes with OCD (Jafari, Mohammadzadeh \& Yaghubi, 2010). Buzzella, May and Pincus (2011) reported that more severe OCD symptoms and specific obsessive compulsive symptoms such as aggressive, sexual, and religious obsessions have been related to co-morbid depression and OCD in adults studied by other researchers. Depression can cause unpleasant states of mind and can make individuals 'abilities less effective to start their everyday tasks in general (Guilbert, 2007).

Depression presents fatigue, pain, sleep disturbance, memory and cognitive dysfunction, learning and intentional problems, and relationship disruption. Cognitive impairment was indicated by considerable numbers of patients with depression (Gualtieri \& Morgan, 2008) and verbal working memory(WM) dysfunction continued in older depressed patients even after their improvement by antidepressant therapy (Butters, Houck ,Mulsant, Nebes, Pollock, Reynolds \& Zmuda, 2003).

Depression spreads through students and affects their educational achievement. Aghakhani and Baghaee (2000) studied 700 medical sciences students at Azarbayejan Gharbi university and found that 53 percent of such students suffered from degrees of depression.

Brown (2007) pointed to the important role of personality factors such as self-esteem, self-efficacy, extroversion , introversion, motivation, extrinsic and intrinsic motivation, and anxiety in language learning. LLS act as the middle between individual learner differences and learning outcomes (Ellis, 1990).

There are six kinds of strategies, which are memory, compensation, affective, social, cognitive, and meta-cognitive strategies (Oxford, 1990). Memory, cognitive, and compensation strategies directly involve the target language and learners implement them differently for various purposes. Chen(2011) mentioned different strategy groups including cognitive, meta-cognitive, memory, social, compensation and affective within the three stages of writing. They include prewriting strategies, while writing strategies and revising strategies. In this study, researchers focus on cognitive strategy use in second language (L2) writing. Chamot and O'Mally(1996) defined cognitive strategies including elaborating on prior knowledge, making inferences, and using imagery or linguistic transfer as strategies used by learners to achieve language and accomplish content tasks. This kind of strategies are more directly associated with the individual learning tasks that involve making predictions, translating, summarizing, linking with prior knowledge or experience, applying grammar rules, and guessing meaning from contexts. They refer to mental activities or processes used by learners to acquire, retain, and retrieve different types of knowledge and performance (Rigney, 1978 as cited in Suradijono, 2003).

Lee (2010) and Liu (2009) pointed to different factors such as age, sex, attitude, aptitude, learning stage, task requirements, teacher expectation, learning styles, individual differences, motivation, cultural differences, beliefs about language learning, and language proficiency cultural background, task type, and learning style that influence use of LLS studied by most researchers.

Cohen (1992) stated that "there is need for more routine collection of information on sex, ethnicity, age, degree of 
language learning experience, world knowledge, motivation, anxiety, beliefs, attitudes, and learning style along with data on the learning environment and teacher variables" ( $p .11)$.

LLS are directly tied to the learner's underlying learning styles such as general approaches to learning and other personality-related variables like anxiety and self-concept of the learner (Brown,1991, as cited in Cohen, 1996). Researcher such as Fazeli (2012) considered personality factors and studied the overall relationships between use of LLS and personality traits of the female university level learners of the English language as a university major. He found a positive relationship between cognitive strategy and traits including openness to experiences and conscientiousness, and a negative relationship between neuroticism and cognitive strategy. Due (2012) stated that "in the process of language teaching and learning, individual learner variables interact with each other. Therefore, it is essential to have an overview on their interrelationships that are yet in shortage in reality" (p.1). He studied 157 students from one University in Shandong to find any relationship between English self-concept and language learning strategies. The result of her study indicated general English self-concept, English speaking self-concept and English pronunciation self-concept had positive relationships with the cognitive strategy.

Chang (2005) studied 307 English majors to find relationship between motivation and LLS among college students of English in Taiwan. Chang found a positive relationship between intrinsic motivation and cognitive strategy. His study revealed that integrated motivation and interjected motivation, which refer to learners` performing certain behaviors to obtain self-esteem, have a positive relationship with cognitive strategies. Kafipour, Nasiri and Zarei (2011) studied 87 students selected through random sampling to determine the effect of instruction in cognitive and meta-cognitive strategies on the students' educational self-esteem and academic performance. They found that cognitive and metacognitive strategies compared to the usual methods of learning increase the educational self-esteem of the students and they found a significant difference between the mean score of educational self -esteem of the students who used cognitive and meta- cognitive strategies and that of the control group. Kafipour and his colleagues pointed to some researchers ' belief that instructing cognitive and meta-cognitive strategies have a different effect on the students' selfesteem. The students who benefit from such strategies are hard working, persevering, and responsible students (Kafipour, et al. 2011). The use of the writing strategies among Iranian undergraduate EFL (English as a Foreign Language) writers with "high anxiety" and "low anxiety" were examined. The results of study show that the writers with "high anxiety" made less use of cognitive strategies compared with the writers with "low anxiety group (Yaghoubi, 2003) .

Anxiety is a psychiatric condition which is studied by Ghasem zade and Kaviyani (2003). They found that 58/3 percent of patients with anxiety have a kind of co-morbidity of depression. People with OCD indicate reduced levels of social functioning which range from reduced levels of employment, poor social and family interactions such as marriage failures, to high levels of associated emotional problems like depression and co-morbid anxiety disorders, and reduced levels of general mental health compared to the normal population (as cited in Broderick, 2012).

Jamshidian (2012) studied a group of 128 students who were all Persian native speakers aged 24-45. She found that 59/37 percent of EFL students experienced degrees of depression and 34 percent of those experienced degrees of OCD and it subgroups. Haji reza and Mirhasani (2009) examined 98 participants majored in English translation Spanish, Persian literature, and psychology and found a negative relationship between depression and vocabulary recall. Haji reza and his colleague (2003) concluded that increasing depressive symptoms among students decreased their ability of vocabulary recall. Biological, genetic, and psychosocial factors lead TEFL students to mental health problems. Based on the book Teaching Students with Mental Health Disorders (2001), psychosocial factors include family functioning and specific distressing life events or environmental stress. Students may feel anxiety and depression because they can not reach proficiency in at least one of the four skills including reading, listening, speaking and writing. There have been empirical studies on factors such as motivation, self-esteem and anxiety that influence cognitive strategy use, but little research has been done on the psychological conditions such as OCD and depression.

\section{Method}

\subsection{Participants}

Seventy and two intermediate students participated in this study. They were chosen from the EFL postgraduate and undergraduate population at Islamic Azad university, Najafabad branch, Iran, for the year 2012 to 2013. They consist of 30 males and 57 females, between the ages 24-45. They were selected through random sampling. It should be mentioned that both age and gender effects were not considered in this study. 


\subsection{Materials}

The materials in this study were Quick Oxford Placement Test (QOPT), Beck Depression Inventory (BDI), Modsley Obsessive Compulsive Inventory(MOCl), writing strategy questionnaire, Semi- structured interview.

\subsubsection{QOPT}

In order to find the proficiency level of participants, the researcher used version 2 of QOPT developed by Oxford University Press and University of Cambridge Local Examination Syndicate(2004). The researchers computed Cronbach's Alpha by SPSS21. It showed that the instrument enjoys a high degree of internal consistency (0.74). QOPT is divided into two parts: part 1 (Questions 1- 40) and part 2 (Questions $41-60$ ). Participants perform on part 2 only if they finish part 1 without problems. As a whole, this 60-item multiple-choice test determines and homogenizes the participants in terms of English proficiency level. It took 30 - 45 minutes. Based on QOPT criterion, researchers classified participants whose grades were 0-17 as beginner, 18-29 as elementary, 30-39 as lower intermediate, 40-47 as upper intermediate, 48-54 as advanced and 54-60 as very advanced.

\section{$3.2 .2 \mathrm{MOCl}$}

MOCI was developed by Rachman and Hodgson (1977). The MOCI is a self-report questionnaire with true-false format developed for evaluating the severity and the type of obsessive-compulsive symptoms. The test includes 30 dichotomous items. The total score for this questionnaire change from 0 to 30. The questionnaire has four subscales: Checking (9 items), Cleaning (11 items), Slowness (7 items), and Doubting (7 items; Rachman \& Hodgson, 1977). The sum of the items for the four subscales is 34 , because four items are included in the two subscales (Rachman et al. 1977). The $\mathrm{MOCl}$ has satisfactory internal consistency and test-retest reliability (Burns \& Sternberger, 1990 cited in Flament \& Irak, 2009). Dadfar (1380) reported that MOCI has the reliability of 0.84 and validity of 0.87.

\subsubsection{BDI}

BDI (Beck \& Steer, 1987) is a 21-item self-report scale that evaluates the severity of depression. Scores of 10 or less are considered as normal while scores of 20 or greater suggest the presence of clinical depression. The BDI has excellent reliability and validity and is widely used in clinical research (Beck, Garbin \& Steer, 1988 cited in Abramowitz \& Deacon, 2006). The reliability and validity of BDI are reported as 0.70 and 0.84 respectively in Iran (Goudarzi, 2002).

\subsubsection{Writing strategy questionnaire}

Another instrument is writing strategy questionnaire employed to assess the cognitive strategies of participants and Adbollahzade (2010) developed it. Cronbach's Alpha showed that the instrument enjoys a high degree of internal consistency $(0.87$; Adbollahzade). It consists of 43 items which determine different strategies using in writing. One of them is cognitive strategies that are focus of this study.

\subsubsection{Semi- structured interview}

MOCDI gave information about the severity of OCD that may be found in all learners because even normal learners may experience the severity of OCD. The researcher investigated differences between normal learners and learners suspected to have OCD. Then the researcher selected 36 intermediate learners whose severity of OCD was less than 10 and 36 intermediate learners whose severity of OCD was 10 or more than 10. After that, she interviewed with all members of two groups. Using semi - structured interview helped the researcher to classify learners into normal learners and learners suspected to have OCD.

\section{Procedure}

The researchers had to administer the test and questionnaires during the class time. Full cooperation of the learners and teachers helped the researcher to obtain the considered data. In general, the researchers collected the data in three phases. 


\subsection{Phase one}

In order to control the effect of proficiency levels, the researcher determined the proficiency levels of participants. In the first session, 138 learners were selected through random sampling. Then, they took the QOPT, and it took 30-45 minutes. Generally, the number of learners at different proficiency levels was determined. Finally, 93 intermediate learners were selected.

\subsection{Phase two}

In second session, $\mathrm{MOCl}$ and $\mathrm{BDI}$ were administered to determine the severity of $\mathrm{OCD}$ and the severity of depression. Participants were asked to answer correctly. Based on the keys of the questionnaires, researchers determined not only the severity of OCD and depression but also the severity of OCD subgroups for each participant.

\subsection{Phase three}

In the third session, wiring strategy questionnaire was distributed among participants. They were asked to indicate the degree to which they agree with each statement by circling the appropriate scale including1 strongly disagree, 2 disagree, 3 neither agree nor disagree, 4 agree and 5strongly agree. They should not answer how they think they should be, or what other people do. The researcher told them that there was no right or wrong answers to these statements.

\subsection{Phase four}

In order to draw a comparison between learners with $O C D$ and normal learners in writing strategy use, the researcher should find student with OCD. Because $\mathrm{MOCl}$ determined the severity of OCD in participants and it does not determine learners with $O C D$, in order to differentiate learners with OCD from normal learners, the researcher selected 36 individuals whose severity of OCD was below 10 as well as those whose severity of OCD was 10 and above 10. Abedi (2013) developed the following questions based on MOCDI. The researcher asked the following five questions to find learners who suffer OCD and need a psychologist or even a psychiatrist to free themselves from OCD symptoms.

1. Do you have bad thoughts about death and God?

2. Do you wash excessively?

3. Do you check every things?

4. Do you store something up?

5. Are you sensitive to accuracy and ordering?

\section{Results}

Based on the results of QOPT, the proficiency level of participants was calculated. Generally the number of participants was determined at different proficiency levels. Table 2 shows the proficiency level of participants.

Table 1. QOPT statistics

\begin{tabular}{cc}
\hline Valid & 129 \\
\hline Missing & 9 \\
\hline
\end{tabular}

Table 2. QOPT

\begin{tabular}{lccc}
\hline & Frequency & Percent & Valid Percent \\
\hline lower intermediate & 68 & 49.3 & 49.3 \\
upper intermediate & 25 & 18.1 & 18.1 \\
advanced & 36 & 26.0 & 26.0 \\
Missing & 9 & 6.5 & 6.5 \\
Total & 138 & 100.0 & 100.0 \\
\hline
\end{tabular}

Based on table 2, the researchers selected a group of 93 intermediate students including lower and upper intermediate. 
As only a few advanced students were left, they were excluded from further analysis.

Table. 3 shows descriptive statistics of performance of normal people, people with OCD and people with depression in using cognitive strategies.

Table 3. Descriptive Statistics of Performance of Normal Students, Students with The severe degrees of OCD and Students with The severe degrees of Depression in Using Cognitive Strategies

\begin{tabular}{ccccc}
\hline students.with.OCD & Depression & Mean & Std. Deviation & N \\
\hline OCD & Normal & 29.00 & 1.414 & 2 \\
& Depressed & 29.35 & 5.989 & 23 \\
Normal & Total & 29.32 & 5.743 & 25 \\
& Normal & 28.67 & 4.318 & 30 \\
& Depressed & 30.65 & 2.621 & 17 \\
Total & Total & 29.38 & 3.882 & 47 \\
& Normal & 28.69 & 4.185 & 32 \\
& Depressed & 29.90 & 4.845 & 40 \\
& Total & 29.36 & 4.573 & 72 \\
\hline
\end{tabular}

Note*. Correlation is significant at the 0.05 level (2-tailed).

The results of descriptive statistics show that there are no significant mean differences between normal people, people with OCD and people with depression in using cognitive strategies in writing. Table 4 shows the results of comparison between normal people, people with OCD and people with depression in using cognitive strategies.

Table 4. The Comparison Between Normal Students, Students with the Severe Degrees of OCD and Students with the Severe Degrees of Depression in Using Cognitive Strategies

\begin{tabular}{lccccc} 
Source & Type III Sum of Squares & df & Mean Square & $F$ & Sig. \\
\hline Corrected Model & $42.845^{\mathrm{a}}$ & 3 & 14.282 & .674 & .571 \\
Intercept & 21780.169 & 1 & 21780.169 & 1027.248 & .000 \\
Students with OCD \& normal students & 1.468 & 1 & 1.468 & .069 & .793 \\
Students with depression\& normal students & 8.528 & 1 & 8.528 & .402 & .528 \\
Error & 1441.766 & 68 & 21.202 & & \\
Total & 63554.000 & 72 & & \\
\hline
\end{tabular}

Note .a. $R$ Squared $=.029$ (Adjusted $R$ Squared $=-.014$ )

The results of ANCOVA reveal that there is no difference between people with $O C D$, and normal people in using compensation strategies $F(1,72)=0.069, p=0.793$ and there is no difference between people with depression and normal people in using cognitive strategies $F(1,72)=0.402, p=0.528$.

\section{Discussion}

The current study investigates the differences between TEFL students with mental health disorders and normal students in cognitive strategy use in L2 writing. A group of 130 female TEFL postgraduate and under graduate students of Najafabad Branch, Islamic Azad University participated in this study. 72 intermediate students were selected through random sampling. The materials used in this study were QOPT, MOCl, BDI, writing strategy questionnaire and semistructured interview. The subjects' OCD and depression scores were computed respectively. At the same time, cognitive strategies for each subject were computed.

The results of this study are the first hand results that follow mental problems including depression, OCD and its subgroups in learning language. There is not a large amount of evidence in this regard, but the results of this study can be supported by a review of the similar studies. Cope, Horwitz and Horwitz (1986) pointed to foreign language anxiety and they believed that there is a relationship between foreign language anxiety and three related performance anxieties: 1) communication apprehension; 2) test anxiety; and 3) fear of negative evaluation. They pointed to the term specific anxiety reaction used by psychologists in order to distinguish people who are generally anxious in a variety of situations from those who are anxious only in specific situations. 
Yaghoubi (2003) found that high anxiety effect the learners' choice of learning strategies. Anxiety is recognized as a psychological disorder in the field of psychology. Although Cope, Horwitz, Horwitz and Yaghoubi studied the effect of anxiety on learning foreign language, they did not consider anxiety as a psychological disorder. Thoughts related to anxiety make people with OCD do obsessive actions, resulting in decreasing the severity of anxiety (Abedi , Esfahanni \& Neshatdoust, 1389). In contrast with Cope, Horwitz, Horwitz and Yaghoubi 's idea, the current study focuses on psychological disorders such as OCD. Jamshidian (2012) found that 34 percent of EFL students experienced degrees of OCD and it subgroups. The results of this study suggest no difference between students with OCD and normal students in using cognitive strategies. Based on DeCaria, Hollander and Liebowitz (1989), OCD subgroups are shown as having impairments in different areas of cognitive functioning. When students write in English, they use cognitive strategies for elaborating on prior knowledge, making inferences, and using imagery or linguistic transfer, translating, summarizing, linking with prior knowledge or experience and applying grammar rules. They refer to mental activities or processes used by learners to acquire, retain, and retrieve different types of knowledge and performance. It seems that inferior cognitive functions in OCD can not lead to significant difference between students with OCD and normal students in cognitive strategy use.

According to Ghasem zade and Kaviyani (2003), 58/3 percent of patients with anxiety have a kind of comorbidity of depression. A cross sectional study conducted by Ghamari, Mohammadbeigi and Mohammadsalehi (2010), the results of their study showed that there is a significant relationship between general health, physical health and depression scores with educational success. Haji reza and Mirhasani (2009) studied 98 participants majored in English translation Spanish , Persian literature, and psychology and found a negative relationship between depression and vocabulary recall. Moreover, the results of their study indicated a negative relationship between depression and abstract vocabulary recall. The Hamilto depression rating scale was used in their study to measure the severity of depression. They did not consider depression as a psychological problem. They did not describe how it affects memory and couses memory loss or poor memory in people with depression. Haji reza and Mirhasani (2003) concluded that an increase in depressive symptoms among students decreased their ability of vocabulary recall.

Hysenbegasi, Hass and Rowland (2005) found a pattern of increasing interference of depression symptoms with academic performance that is experienced by depressed students. In fact, they found a significant relationship between depression and academic performance. There are two theories including Hopelessness theory and Beck's theory that describe depression. Based on Hopelessness theory, when people make three inferences about negative life events (the stress), they experience symptoms of hopelessness depression such as lack of energy, sleep disturbance, difficulty in concentration, lowered self -esteem and dependency. These inferences include inferences about why the event occurred (causal attribution), inferences about results of the occurrence of the event (inferred consequences) and inferences about the self given that the event occurred (inferred characteristics about the self). When stable and global attribution for a negative life event and attachment of high importance to event increase, the person will be hopeless and symptomatic for a larger amount of time than usual. The inferences about the self, which play a central role in Beck's theory, refer to inferences a person draws about his or her own worth, personality and abilities from the fact that a particular negative life event occurred. "Beck's theory proposed a stress component in which dysfunctional attitudes are hypothesized to interact with negative events lead to elevations of depressive symptoms" (Abramson, Hankin, Miller, \& Haeffel ,2004 , p.310).

According to Marsden, Mitchel and Myles (2013), in Krashen`s Affective Filter hypothesis, an important role of emotion was highlighted in second language learning. Based on the Affective Filter Hypothesis, when learners are different with respect to the strength or level of their affective filters, there is a relationship between affective variables and the process of second language acquisition. Abedi and his collegues (2012) found that 59/37 percent of EFL students experienced degrees of depression. They found that learners with depression try to retrieve information from their memory or to use memory strategies in their writing but limitation of their memory make them use their memory strategies less effectively. Substantial numbers of patients with depression indicate cognitive impairment (Gualtieri \& Morgan, 2008). The results of this study indicates no difference between people with depression and normal people in using cognitive strategies. Based on the researchers' knowledge, there is no study to support this finding. Although, people with depression indicate cognitive impairment, both students with depression and normal students prefer to use cognitive strategies in the same way. All people in two groups need to elaborate on prior knowledge, to make inferences, and to use imagery or linguistic transfer, to translate, to summarize, to link with prior knowledge or to experience and to apply grammar rules. Cognitive impairment may influence choice of these areas but its effect may not significant to differentiate students with depression and normal students. 


\section{Conclusion}

Researchers conducted this study to address the important issue of psychological problems in Iranian TEFL learners in order to find the differences between TEFL students with mental health disorders and normal students in cognitive strategy use in L2 writing. The research shows no evidence for significant mean difference between normal people, people with OCD and people with depression in using cognitive strategies in writing between the severity of depression and cognitive strategy use.

\section{Implications}

The findings of the study highlight the importance of psychological problems in the process of learning to language teachers and give information about mental health problems to help learners in this respect.

\section{Limitations}

This study like any other study had a number of limitations. All phases of the research procedure should be applied during class time; however, class time limitation was the first limitation of this research. The second limitation of this study was the shortage of literature on the topic.

\section{Suggestions for Further Studies}

Based on the results of this study, some suggestions are made for further research. Researchers offer the longitudinal study to closely investigate the relationship between psychiatric conditions and learners ' writing strategy use. In addition, further work is required to compare people with depression and normal people in using writing strategies.

\section{References}

Abdollahzadeh, E. (2010). Undergraduate Iranian EFL learners' use of writing strategies, Writing \& Pedagogy, 2(1). [Online] Available: http://www.equinoxpub. com (July 7, 2010).

Abedi, M. R.,Esfahanni, M. \& Neshatdoust, H. T. (2010). Practical manual for treatment of Obsessive-Compulsive Disorder, 2(17).

Abramowitz, J. S. \& Deacon, B. J. ( 2006). Psychometric properties and construct validity of the Obsessive-Compulsive Inventory Revised: Replication and extension www.ncbi.nlm.nih.gov Anxiety Disorders. Clinical , 20,1016-1035.

Abramson L. Y., Hankin B.L., Haeffel G. J. \& Miller N., (2004). Cognitive Vulnerability-Stress Theories of Depression:Examining Affective Specificity in the Prediction of Depression Versus Anxiety in Three Prospective Studies. Cognitive Therapy and Research, 28, 3, pp. 309-345

Aghakhani, N. \& Baghaeei, R. (2000). The Degree of Depression in Urmia University of Medical Sciences Students. The Mood Disorders Nursing News. from prevention to rehabilitation.

Beck, A. T., \& Steer, R. A. (1987). Beck Depression Inventory Manual. San Antonio, TX: Psychological Corporation.

Beck, A. T., Steer, R. A., \& Garbin, M. G. (1988). Psychometric properties of the Beck Depression. Inventory: twenty-five years of evaluation. Clinical Psychology Review, 8, 77-100.

Boalhori M., Dadfar, M., Malakoti J. , Nazadebiyak (2001). The study of the epidemiology of symptoms of Obsessive Compulsive Disorder. Journal of Clinical Psychology and Psychiatry;7:32.

Broderick, J. M.( 2012).Disgust and Contamination Fear Based Obsessive-compulsive Disorder: An Investigation. UNS WORKS.

Brown, H.D. (2007). Principles of Language Learning and Teaching. New York: Longman

Brown, H. D.(1991). Breaking the Language Barrier. Yarmouth, ME : Intercultural Press.

Butters, M. A., Houck, P. R., Mulsant, B. H., Nebes, R. D., Pollock, B. G, Reynolds III, C.

F., \&., Zmuda, M. D., (2003). Persistence of cog-nitive impairment in geriatric patients following antidepressant treat-ment: A randomized, double-blind clinical trial with nortriptyline and paroxetine. Journal of Psychiatric Research, 37, 99-108. doi:10.1016/S0022-3956(02)00085-7

Buzzella, B. A., Ehrenreich-May, J. \& Pincus, D. B.(2011). Co morbidity and family functioning in children with selective mutism. Child Development Research.

Chamot, A.U., \& O'Malley, J. M. ( 1996). Implementing the Cognitive Academic Language Learning Approach (CALLA). In R. Oxford (Ed.), Language Learning Strategies. Around the World: Cross-cultural Perspectives (pp. 167-174). Manoa: University of Hawaii Press.

Chang, H-H. (2005). The relationship between extrinsic/intrinsic motivation and language learning strategies among college students of English in Taiwan(Master's thesis).

Chen, Y. (2011). Study of the writing strategies used by Chinese non-English Majors. Theory and Practice in Language Studies, 1 (3), 245-251. 
Cope, J. A. Horwitz, E. K., \& Horwitz, M. B (1986). Foreign language classroom anxiety. The Modern Language Journal, 70(2), 125-132.

Cohen, A. D. (1996). Second Language Learning and Use Strategies: Clarifying The Issues(Report No.254). Minneapolis: Center for Advanced Research on Language . Acquisition, University of Minnesota

Cohen, A. D. \& Oxford, R. L. (1992). Language learning strategies: Crucial issues of concept and classification. Applied Language Learning, 3(1-2),1-35

Csigó, K. ,Demeter, G. , Harsányi, A. , Németh A.\& Racsmány M., (2011). An experimental study of prospective memory in obsessivecompulsive disorder, Journal of Clinical and Experimental Neuropsychology,. 33(1), 85-91. [Online] Available: http://www. tandfonline.com/loi/ncen20

DeCaria, C.M, .Hollander, E., \& Liebowitz, M.R. (1989). Conceptual and methodological issues in studies of obsessive-compulsive and Tourette's disorders. Psychiatric Developments, 4, 267-296.

Du, M. (2012) . A Study of the Relationship between English Self-concept and Language Learning Strategies, Journal of Language Teaching and Research,. 3. 3, pp. 508-517, May .Academy Publisher Manufactured in Finland. doi:10.4304/jttr.3.3.508-517

Ellis, R. (1990). Understanding second language acquisition. Oxford: Oxford University Press

Fazeli, S. H. (2012). The overall relationships between the use of English language . learning strategies and personality traits among the female university level learners of English language as a university major Indian, 1, 7. [Online] Available: www. elsevier .com/lo cate/system

Flament, M. F. \& Irak, M. (2009). Attention in sub-clinical obsessive- compulsive checkers. Journal of Anxiety Disorders, 23 ,320-326. [Online]Available:http://www.tandfonline .com

Ghasem zade, A.\& Kaviyani , A. (2003). Co morbidity of Depression and Anxiety in Iranian society. Tehran University of Medical Sciences (TUMS). 171-177: (3)61. [Online] Available: www.SID.ir

Ghamari, F. Mohammadbeigi, A. \& Mohammadsalehi, N. (2010). The association between mental health and demographic factor with educational in the students of Arak universities. [Online] Available: www.SID.ir.

Ghanei, S. , Mohamadpour, M. \& Shariatifar, N. (2003). The survey of prevalent of depression and correlation with social \& educational factors in Mashhad medical student, Journal of Gonabad Medical Faculty and Health Services.

Goudarzi, M. (2001).Validity and reliability of the Beck hopelessness scale in a sample of Shiraz University students. Shiraz University journal of humanistic and social sciences; 32(17), 1-12.

Gualtieri, C. T., \& Morgan, D. W. (2008). The frequency of cognitive impairment in patients with anxiety, depression, and bipolar disorder: An unaccounted source of variance in clinical trials. The Journal of

Guilbert, P. (2007). Psychotherapy and counselling for depression (3rd ed.). SAGE Publications Ltd. Clinical Psychiatry, 69, $1122-1130$. doi:10.4088/JCP.v69n0712

Hajireza, S. \& Mirhassani S.A. (2009). The Relationship between Depression and Vocabulary Recall of Iranian University Students. Foreign language teaching journal 1387;23:56-49.

Hysenbegasi, A. , Hass, S. L.\& Rowland, C.R. (2005). The Impact of depression on the academic productivity of university students. The Journal of Mental Health Policy and Economics J Ment Health Policy Econ Journal, 8, 145-151

Jafari, I. \& Mohammadzadeh, A. \& Yaghubi, H. (2010). Comorbidity of depression and obsessive compulsive disorder subtypes in nonclinical samples. Journal of Fundamentals of Mental Health, , 2(46), 506-13.

Jamshidian, F. (2013). The relationship between the severity of OCD and depression with writing performance and writing strategies used by Iranian EFL learners (Unpublished Master's Thesis). Islamic Azad University, Najaf Abad Branch, Najafabad, Iran.

Kafipour, R. , Nasiri, E. \& Zarei, E., (2011) Self-esteem and academic success as influenced by reading strategies. English Language Teaching 5, 2.

Koestern, R. , Senecal, C. \& Vollerand, R. ( 1995). Self- Regulation and Academic Procrastination, The Journal of Social Psychology, 135(5),607-619.

Lee, K. C. (2010). An Overview of Language Learning Strategies. Anadolu Journal of Educational Sciences International, 7, $132-152$.

Liu, M . (2009). An Investigation of Cognitive and Meta-cognitive Strategy Use : Changes And Differences Indonesian. Journal of English Language Teaching 5. 2.

Marsden E. , Mitchel R. \& Myles F. (2013) . Second Language Learning Theories. Taylor \& Francis Group

Oxford, R.L.(1990). Language Learning Strategies: What Every Teacher Should now.Boston: Heinle \& Heinle

Rachman, S. \& Hodgson, R.J. (1988). Obsessions and compulsions. Englewood Cliffs, NJ:Prentice Hall Schemck, RIndividual differences and learning strategies. InC.Weinstein,E.Goetz,\&P.Alexander (Eds.), learning and study Strategies.N.Y.: Accademic Press.

Rigney, J.W. (1978). "Learning Strategies: A Theoretical Perspective" in Learning Strategies. H. F. O’Neil Jr. (Ed.). New York: Academic Press.

Schmeck, R. (1990). Individual differences and learning strategies. In C. Weinstein, E.Goetz, \& P. Alexander (Eds.), Learning and Study Strategies. N.Y.: Academic Press, 171-191

Suradijono, S. R.(2003). How does courseware's design affect learners' cognitive-strategy ?. Makara, social humaniora, 7, 1.

The book Teaching Students with Mental Health Disorders (2001). Ministry of Education.Special Programs Branch

Wenden, A. L. (1987a). Conceptual background and utility. In A. L. Wenden \& J. Rubin . (Eds.), Learner strategies in language learning, (pp. 3.13). Englewood Cliffs,NJ: Prentice-Hall.

Yaghoubi, S. (2003). On the relationship between writing anxiety, writing strategies, and sentence complexity (Unpublished Master's Thesis). University of Tehran 